\title{
Public(s): A Concept Explication for Modeling Public Management
}

Kyung Jung Han*

Missouri School of Journalism, University of Missouri, USA

\begin{abstract}
With the advent of web and social media channels, the concept of public has become more complicated and even problematic. Thus, this study sheds light on the term public to reduce ambiguity in applying the concept to the study and practice of public relations, reflecting the long tail of publics. Based on McLeod and Pan'sconcept explicationframework, this study suggests a conceptual public management model for scholars. The model implies that public varies across individuals, organizations, contexts and time.
\end{abstract}

Keywords: Public; Public relations; Concept explication

\section{Introduction}

As Web communities, formed in blogs and social networking sites (e.g., Twitter, Facebook, Pinterest, etc.) via various electronic devices such as mobile phones, iPad, and other new media, have increased dramatically over the past five years, communicative relationships and methods of communicating, consequently, have become more complicated. Solis and Breakenridge [1] predicted such a changing pattern of public activities in the early era of social media and defined the phenomenon as a metaphor, long tail. Here, the long tailimplies the coexistence of many small businesses. The authors pointed out that niche business strategies for organizations should be discussed with considering a new communicative pattern influenced by organizationpublic relationships. Thus it is not surprising that scholars and PR practitioners make efforts to understand publics in a given situation to build and maintain a positive relationship between publics and organizations.

Although public is one word constructing public relations and public opinion, there are few scholars or practitioners who can define it clearly. This is because the concept of public, per se, is very complicated, in addition to the fact that many factors should be considered (e.g., identification of the public group, size, relationship with the organization, etc.). To fill the gap within concept and research using public, this paper seeks to explicate the public in public relations.

To conceptualize public, this paper will utilize McLeod and Pan's [2] concept explication procedure. They suggest six steps for concept explication: identifying the concept, searching the literature, examining empirical properties, developing a tentative conceptual definition, defining the concept operationally, and gathering data. Here, except for the last step-gathering data, this study follows these steps and aims at narrowing down the definition of public.

Therefore, this explication aims at helping both public relations scholars and practitioners understand public further. For public relations scholars, it is expected to be a reference to build a model of public management; for public relations practitioners, this paper is meaningful to provide ideas in order to explore better strategies and to achieve their short-term and long-term goals. Given theoretical perspectives within and outside of public relations and empirical discussion, this paper looks at the cluster constructing the concept public. Through this, as considering the linkage between theory, observation, and research, it strengthens the times. Besides, it connects related and derived concepts that are used, but not clear. Accordingly, this explication aims at making them as clear as possible [3].

\section{General Background}

Public is a mega-concept because it has conceptual clusters entangled with a number of unspecified concepts. These concepts often have potential communication problems if there are misunderstandings between the receiver (listeners and readers) and the sender [2].

Public is often used as the opposite of private. It is regarded as the audience of a newspaper, magazine, or television station [4]. Public is also defined as groups of employees, communities, or consumers, without considering the different kinds of employee, community, or consumer publics [5]. In other words, publics refer to stakeholders and are used as stakeholders interchangeably [6-8].

Public is sometimes misused in place of similar words indicating groups of people such as crowd, mass, and community. However, these concepts are not the same because each word includes different implications. Blumer [9] explained that mass includes many facets. A mass has four distinctive features: it is heterogeneous and its members come from all groups of a society; the individuals do not know each other; they are spatially separated from one another; and a mass has no definite leadership. According to Glynn and his colleagues' book [10], crowds share their emotional experience, butmasses are isolated interpersonally. In contrast, Schramm and Roberts [11] described public as a specific group of people who concern a situation in a particular time.

Meanwhile, public is distinguished from community as a narrower concept. Public is generally political and forms out of communities, whereas publics may later evolve into a community and become broader beyond a single issue [12].

\section{Literature Review}

In order to focus on the public in public relations specifically, mass communication is included in non-public relations in this paper; in other words, mass communication-oriented mass media, and

*Corresponding author: Kyung Jung Han, Missouri School of Journalism, University of Missouri, USA, Tel: +1-573-882-2121; E-mail: khyc2@mail.missouri.edu

Received July 08, 2014; Accepted September 01, 2014; Published September 08, 2014

Citation: Han KJ (2014) Public(s): A Concept Explication for Modeling Public Management. J Mass Communicat Journalism 4: 215 doi:10.4172/21657912.1000215

Copyright: (c) 2014 Han KJ. This is an open-access article distributed under the terms of the Creative Commons Attribution License, which permits unrestricted use, distribution, and reproduction in any medium, provided the original author and source are credited. 
communication with the masses indicating a more general meaning of public. On the other hand, public relations does not simply use public as the antonym of private, but uses the term in reference to the relationship between organizations and the involved issues. Therefore, given that the concept of public is utilized in non-public relations to public relations, this paper seeks to concrete the meaning of public.

\section{Public in non-public relations}

In terms of sociology and politics, public means the general body of free citizens in a given society or in some smaller geographical space. The members of a public are described as those who are free to associate and express themselves in democracy [13]. More generally, public is used with other words as a compound. For example, public organization and public school represent the opposite meaning of private. However, when it is used as in public affair/administration, it stands for the general public as a group of people and sometimes indicates a specific group of people when decision makers need to discuss certain issues. On the other hand, Mcquail [13] also explained that public interest is used to consider the goal of media because the media should meet the needs of its audiences, but within ethical, ideological, political, and legal considerations. Here, public is a specific target group of audiences.

A sociologist and philosopher, Jürgen Habermas [14] defined public sphere with public opinion. These concepts are helpful to understand the public's communication and movement sphere. According to Habermas et al. [14], the public sphere is a realm of our social life and the place where public opinion can be formed. All citizens can access and behave as a public body in public sphere. The differences in power between publics exist. Habermas also stated that newspapers, magazines, radio, and television are the media of the public sphere. In brief, the public sphere is where public association and debate exist, leading to the formation of public opinion and political movement. The media is the key institution of the public sphere [13].

Blumer [15] described the meaning of a public as a group of people who confront an issue, are divided in their ideas depending on their stance on how to meet the issue, and engage in discussion over the issue. Similarly, Dewey [16] defined a public as a group of people who face a similar problem, recognize that the problem exists, and organize to do something about the problem. In sum, a public is regarded as a group of people facing a problem/issue, judging the problem/issue, and doing something against the problem/issue.

\section{Public in public relations}

A public is SPECIFIC. In public relations, the word public is sometimes used as the plural publics as a jargon of the field, indicating multiple groups of public. Depending on where the point of interest is in a given situation, public relations practitioners and scholars sometimes call publics other terms, such as audiences, consumers, and so on. Given that Moffitt [17] distinguished audiences or publics from individuals, a public is defined as a group of people who have a relationship and importance to an organization. According to Grunig and Hunt [5], a "general public" is logically impossible. Rather, publics are always specific and face some common problems. GonzelezHerrero and Pratt [18] supported this idea, describing publics as a "group of people who face a common issue".

A public is VOLATILE. It is also a variable concept. In other words, today, it is possible that publics may exist, but tomorrow, they can be replaced by others. Thus, it depends on an organization's practice, and the response of people and organizations in the environment toward the organizational behaviors. Here, public opinion intervenes to stop organizational consequence. McQuail [13] described public opinion as the collective views of a significant part of any public. It is measured by polling, but there are missing parts because opinion is always diverse, dynamic, and variable. Such a perspective can be supported by Murphy's [19] mixed motive games model. Murphy argued that a completely balanced two-way symmetric model is impossible because it is, at last, a zero-sum game between two parties. If one player gains, the other must necessarily lose. Additionally, there are mixed-motive equilibria on a continuum ranging from conflict to cooperation. Through this model, it is possible to understand publics to vary their opinion as the opposite side of organizations. Furthermore, Wilcox, et al. [20] explained about the life cycle of the conflict management from the proactive, strategic, and reactive phase to the recovery phase. It shows that organizations manage a problem, considering the stages, and publics are open to changing their minds as a response to the organizations' practices.

A public THINKS and COMMUNICATES. Blumer [15] insisted that public "behavior" is a key and "consequences" create publics. Because publics judge the given situation and determine how to react or move, they are disclosed by their behaviors. Grunig [21] suggested that detection and behavior are key factors to determine the types of publics. According to the situational theory of publics, he categorized publics into four groups: non-public, latent public, aware public, and active public. A non-public includes none of the conditions mentioned below. A latent public faces a similar situation but does not detect any problem. If a public detects the problem, it becomes an aware public. On the other hand, active public means a group of people who discuss and do something about the problem. Meanwhile, Grunig and Hunt [5] conceptualized the four models of excellent theory from organizational perspective. This theory also considers publics as a communication partner of organizations in the opposite side of the organization. Depending on the balance and direction of communication, there are four types of communication between organizations and publics: press agentry (e.g., propaganda), public information, two-way asymmetric, and two-way symmetric.

A public is LINKED to ORGANIZATIONS. Meanwhile, both Grunig and Hunt [5] and Esman [22] explained the concept of publics with organizational "linkages" to the environment. According to Esman [22], there are four types of linkages that are critical for an organization to survive: enabling linkages, functional linkages, normative linkages, and diffused linkages. Firstly, enabling linkages describes the authority and the resources that enable the organization to exist, such as stockholders, congress, state legislators, community leaders, etc. Functional linkages are divided into input and output linkages. Input linkages mean the internal publics such as employees. In contrast, output linkages include external publics (e.g., consumers, service users, etc.). Next, normative linkages are a group of organizations that face similar problems or share similar values, such as political groups. Finally, diffused linkages are linkages that cannot clearly be identified. Thus, it implies that they arise when organizations have consequences on people. It is also related to public opinion.

A public is still A CLUSTER OF INDIVIDUALS. Although a public is described as homogeneous-different from the heterogeneous mass-they are still a set of the individuals. In reality, an audience is intermingled with diverse cultural, ethic, religious, and socioeconomic attributes. They even have different ages and genders [20]. Kruckeberg and Vujnovic [23] mentioned that historically, there was the spike in communication and transportation, and everyone became nationalized 
or homogenized. At the same time, new means of communication and transportation resegmented communities according to the individuals' commonalities, such as vocations and shared interests.

\section{Empirical Description}

Because public is a key concept in public relations, almost all research has dealt with the public. This means that analyzing how publics are measured is not difficult because there are many studies. However, scholars are likely to focus more on the logic of the research, not the concept of public only. Such fixation on the meaning of public and ignorance of the different emphases on the characteristics of publics may prevent the evolution and explication of public. Hence, scrutinizing the previous empirical studies about it is meaningful.

\section{Specific publics}

Specific publics can be defined depending on a given situation and a particular time. In other words, to define a public of a given situation and a particular time, analyzing the situation should precede all other factors. As mentioned above, conflict management stages can be considered first. Depending on the stages-proactive, strategic, reactive, and recovery-publics' movements can be varied. Furthermore, the Contingency Theory [24] considered several factors to specify publics, such as where publics are involved (internal/external publics) and where the situation is affiliated (internal/external threats).

\section{Volatile publics}

This property of publics is overlapped with measuring specific publics. However, it is more related to a public's attitude [25], intention, and behavior. How it has changed or how it will be changed matters here. For example, Coombs and Holladay [26] examined whether there are differences in publics' judgment on organizations' response strategies in order to assess publics' impressions regarding organizations' public relations practices. Cameron and Yang [27] also examined the effect of support and personal distance-whether it is personal or interpersonalto observe publics' behaviors (active vs. passive).

\section{Thinking and communicating publics}

Through situational theory of publics [21], several independent variables and dependent variables are suggested. For independent variables, problem recognition, constraint recognition, and level of involvement are presented; for dependent variables, information seeking and information processing are suggested. Hallahan [28] insisted that the degree of publics' knowledge defines five publics models on knowledge and involvement: aware publics, active publics, inactive publics, aroused publics, and non-publics. Cancel et al. [24] also mentioned the degree of publics' knowledge. Additionally, publics' willingness to dilute a problem's cause/request/claim, the amount of advocacy, the publics' perception if they are reasonable or radical, etc., are listed as their variables in contingency theory.

\section{Organizational linkages}

To understand the links between publics and organizations, defining organizations is required. What culture they have [24,29], what type of organization they are (non-profit, government, private, etc.), and relationship characteristics such as level of trust, image, and [4,24,30-32].

\section{Individual publics}

This includes the individual factors of publics. Cancel et al. [24] suggested "individual characteristic" as an internal variable of contingency. Grunig [33] conducted a case study that considered the demographic information and other variables to define publics. Wilcox et al. [20] also mentioned age and gender effects in identifying different public groups.

\section{Conceptual Definition}

Through the explication process, we develop the concept of public. Given a conceptual model for pubic management, this study conceptualizes public as shown in Figure 1. Community has a broader meaning than public, so it is placed above public. However, publics are formed out of communities. Individual factors, organizational factors, contextual factors (situation and media), and time factors are determinants of public segmentation.

That is, public is defined as a group of people who are:

- comprised of individuals having different media-use patterns, demographic factors, knowledge, controllability, involvement, and stance on the situation

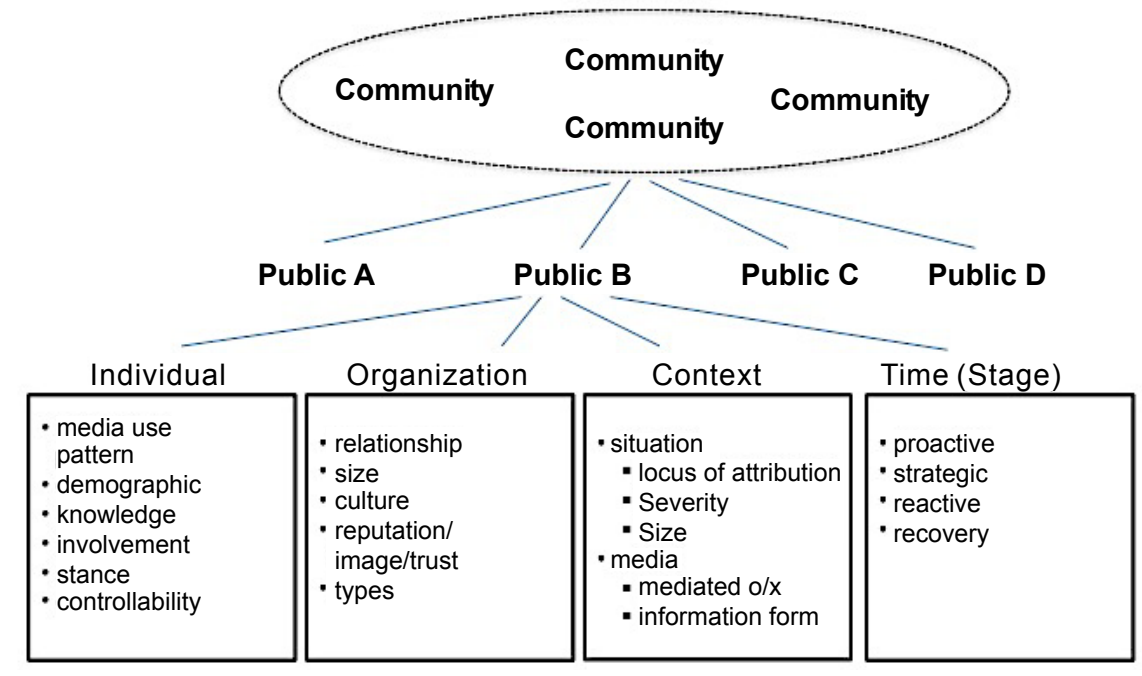

Figure 1: A Conceptual Public Management Model. 
- $\quad$ building relationships with organizations that have their own culture and product category, and interacting with the predisposing factors that evaluate the organization such as reputation, image, and trust

- $\quad$ faced the situation and communicate with organizations via a certain media or direct means

- in a stage of issue/conflict management among proactive, strategic, reactive, and recovery.

This conceptualization is not a fixed process, but a heuristic version. Subcategories and variables may require updating as there is more interaction with surrounding factors such as technology and sociological changes.

\section{Operationalization of Public in Public Relations}

The conceptualized factors of public do not mean all factors should be considered in every research or practice. However, it helps for practitioners to analyze a case and to define publics; it also helps for scholars to design their own studies depending on their point of interest.

As a scholar or a public relations practitioner, for instance, it is possible to study the effect of public persuasion messages created for facilitating public participation, interacting with the trust/image of the organization. It may be asked by a non-profit organization. They may want to build a good relationship with publics and to let them donate further in instances when there is a crisis-for example, flood damage. They can try to test their various message wordings with publics. In particular, mobilizing college students may challenge the organizations to achieve their goals. Thus, testing first before practicing can be effective. Here, the stage of issue management is a reactive phase because the organization is working to minimize the consequential victims through fund-raising.

Firstly, as a contextual factor, a situation analysis can be conducted. The responsibility is not attributed to the organization. However, the victim remains in serious condition. Additionally, mobilizing publics can be a considerably important factor in terms of sticking to a budget and attaining an organizational goal; if enough money is earned, it will be used for these purposes. It helps to set a goal to mobilize publics.

Next, for this research, deciding a target is required as it becomes a sample in research. If there is no limitation when recruiting samples, conducting a study with real people in a real situation is the best condition. In this case, college students are the best interest group for an organization. Then, understanding the sample group is required. What media they use the most and least are the factors the survey should measure. What gender they are, whether they have part-time jobs and how much they earn, and how much they know about the flood damage can be the following questions asked in order to understand the individuals. Next, to measure involvement, it is possible to ask if they knew anyone who was influenced by the flood that recently happened and through their donation and if they predict that they can actually help someone.

In order to measure their relationship with the organization, they can ask how much they know about the organization, how much they trust them, and what image they have of the organization. After that, they can present their messages in a way that is personalized by various strategic factors. Then, the researcher can ask if they are willing to donate or not. That is, the intention to donate can be the dependent variable in this study. On the other hand, individual factors such as media form, message types, organizational image and trust in the organization can be the independent variables.

\section{Discussion}

Since Broom et al. [34] scrutinized the comprehensive meaning of relationships between organizations and publics, there have been few updates that have elaborated on the main concepts in public relations. Thus this study sheds light on the term public to reduce ambiguity in applying the concept to the study and practice of public relations. In order to understand the public in public relations, not only contextual factors, but also individual factors should be considered together. Moreover, the relationship with an organization, the characteristics of the organization and the stages of issue/conflict management need to be analyzed together.

However, this is not the whole explication. Public segmentation asks for more sophisticated standards to understand publics better. As modern examples of media environments, blogs and social media have been key issues for researchers. To understand public behavior, the media's effects on agenda building, publics' media-use behaviors (whether they actively participate and if it's influential), and whether they interact offline by word of mouth and so on are measured [35-37]. However, new social networks are continually created. This requires another update in the factors defining public.

Again, public is not a simple concept. Kruckeberg and Tsetsura [38] argued that globalization from nationalization is now inarguable to understand publics, but a global resegmentation seems to have infinite perspectives on multiple issues. In other words, the clear boundary between public and private has become a confusing and threatening issue. Thus, they asserted that public problems are redefining the culture and the world where we are living. They questioned the concept of publics (plural) in an era of globalism. Publics worldwide have infinite numbers, are volatile, and form immediately and unpredictably. It could lead to chaotic movement with unpredictable power.

However, traditional publics still exist, and publics move as plural groups of people. What we should keep in mind is the coexistence of individual factors. It may strengthen in some media and weaken in other environments with certain factors. Therefore, not only should the explicating of public be continued, but so should strengthening the validity and credibility of the variables constructing the idea, public.

\section{Implications of Defining and Modeling Public}

Through a conceptualization work, the present paper intends to build a public management model and to help public relations scholars understand an overarching meaning of public. Given overall theories that discuss public in their principles, this study offers an overview on how the concept of public has been defined. From conceptual discussions to manipulation of the concept, it contributes to draw a picture of public. It is useful to elaborate on the meaning space that public has. Because the public management model includes factors constructing the complex term public, it can be applied to develop a scale for measuring and defining publics and specified groups in publics. Moreover, scholars can refer this public management model to segment publics with public segmentation theories previously discussed. Furthermore, the current study contributes to use a foundational concept public with a systematic and accurate approach for scholars. If there are any scholars who want to study public with involved variables that have been explored in previous literatures, the present paper can be a basic step to help brainstorm their research. Other than scholars in public relations, it can be a guideline for students studying public 
relations as well as for someone who doesn't know what public means and why publics are accepted jargon in public relations.

The public management model discussed in this paper is timely and useful to public relations practitioners as mentioned in the introduction. In other words, as complex variables should be considered by practitioners increase, taking a systematic approach to public is essential. As an update for public relations practitioners, mobile media and the long-tail pattern need to be reflected in their practices. That is, various factors constructing public and many small businesses influence communication between organizations and publics. Besides, "people in Web communities are listening and leaning, yet at any given time, they are ready to influence their peers by publishing their own interpretation, insight, opinions, and meaningful information" [1]. It means publics become smarter and more active than before, so they require a sophisticated approach from the practitioners. Furthermore, in terms of new media, Yankeelov emphasized the importance of mobile applications to succeed in communication with publics who may adopt new media earlier than practitioners' prediction.

\section{References}

1. Solis B, Breakenridge D (2009) Putting the public back in public relations: How social media is reinventing the aging business of PR. Upper Saddle River, NJ: FT Press.

2. McLeod JM, Pan Z (2005) Chapter 2:Concept Explication and Theory Construction. In Dunwoody et al. (eds.), The Evolution of Key Mass Communication Concepts, Cresskill, NJ: Hampton Press.

3. Chaffee, Steven H (1991) Communication Concepts: Explication. Newbury Park, CA: Sage.

4. Benoit W L, Pang A (2008) Crisis communication and image repair discourse In HornTH \& NeffB (Eds.). Public relations theory: From theory to practice. Boston, MA: Pearson Allyn and Bacon.

5. Grunig JE, Hunt T (1984) Identifying Organizational Linkages to Publics. In Managing Public Relations. New York: Holt, Rinehart and Winston.

6. Fearn-Banks K (2001) Crisis communication: A review of some best practices. In RL Heath and Gabriel Vasquez (Eds.). Handbook of public relations. Thousand Oaks, CA: Sage.

7. Rawlins BL (2006) Prioritizing stakeholders for public relations.

8. Ulmer RR, Sellnow TL, Seeger MW (2007) Effective crisis communication Thousand Oaks, CA: Sage.

9. Blumer H (1946) Collective Behavior. In Lee AM (ed), New Outline of the Principles of Sociology, NY: Barnes and Noble.

10. Glynn CJ, Herbst S, O'Keefe GJ, Shapiro RY, Lindeman M (1999) Public opinion. Boulder: Westview Press.

11. Schramm W, Roberts DF (1971) The process and effects of mass communication. Urbana, Illinois: University of Illinois Press.

12. Hallahan K (2004) "Community" as a Foundation for Public Relations Theory and Practice. Communication yearbook 28: 233-280.

13. McQuail D (2010) McQuail's mass communication theory (6thedn). Thousand Oaks, CA Sage Publications.

14. Habermas J, Lennox S, Lennox F (1974) The public sphere: an encyclopedia article (1964). New Ger Crit.

15. Blumer H (1966) The Mass, the Public, and Public Opinion. In Berelson B and Janowitz M (2ndedn), Reader in Public Opinion and Communication, NY: Free Press.

16. Dewey J (1927) The Public and Its Problems, Chicago: Swallow.

17. Moffitt MA (1994) Collapsing and integrating concepts of 'public' and 'image' into a new theory. Public Relat Rev 20: 159-170.

18. Gonzalez-Herrero A, Pratt CB (1996) An integrated symmetrical model for crisis-communications management. J Publ Relat Res 8: 79-105.
19. Murphy P (1991) The limits of symmetry: A game theory approach to symmetric and asymmetric public relations. J Publ Relat Res 3: 115-131.

20. Wilcox DL, Cameron GT, Reber BH, Shin J (2013) Think Public Relations Upper Saddle River, NJ: Pearson.

21. Grunig JE (1997) A situational theory of publics: Conceptual history, recent challenges and new research. Public relations research: An international perspective 3: 48 .

22. Esman MJ (1972) The Elements of Institution Building. In J. W. Eaton (Ed.) Institution Building and Development, Beverly Hills, CA: Sage 19-40.

23. Kruckeberg D, Vujnovic M (2010) The death of the concept of publics (plural) in 21 st century public relations. Int J Strat Comm 4: 117-125

24. Cancel AE, Cameron GT, Sallot LM, Mitrook MA (1997) It depends: A contingency theory of accommodation in public relations. J Publ Relat Res 9 : $31-63$

25. Rogers RW (1975) A Protection Motivation Theory of Fear Appeals and Attitude Change. J Psychol 91: 93-114.

26. Coombs WT, Holladay SJ (2008) Comparing apology to equivalent crisis response strategies: Clarifying apology's role and value in crisis communication. Public Relat Rev 34: 252-257.

27. Cameron GT, Yang J (1991) The effect of support and personal distance on the definition of key publics for the issue of AIDS. Journalism Quart 68: 620-629.

28. Hallahan K (2000) Inactive publics: the forgotten publics in public relations Public Relat Rev 26: 499-515.

29. White JC, Varadarajan PR, Dacin PA (2003) Market situation interpretation and response: The role of cognitive style, organizational culture, and informationuse. J Marketing.

30. Cancel AE, Mitrook MA, Cameron GT (1999) Testing the contingency theory of accommodation in public relations. Public Relat Rev 25: 171-197.

31. Holtzhausen DR, Roberts GF (2009) An investigation into the role of image repair theory in strategic conflict management. J Publ Relat Res 21: 165-186.

32. Kiousis S, Popescu C, Mitrook M (2007) Understanding influence on corporate reputation:An examination of public relations efforts, media coverage, public opinion, and financial performance from an agenda-building and agendasetting perspective. J Publ Relat Res 19: 147-165.

33. Grunig JE (1997) A Situational Theory of Publics: Conceptual History, Recent Challenges and New Research. In Moss D, MacManus T, and Vercic D (eds.), Public Relations Research: An International Perspective,London: International Thomson Publishing 3: 282-288.

34. Broom GM, Casey S, Ritchey J (1997) Toward a concept and theory of organization-public relationships. J Publ Relat Res 9: 83-98.

35. Austin L, Liu BF, Jin Y (2012) "How Audiences Seek Out Crisis Information: Exploring the Social-Mediated Crisis Communication Model". J Appl Commun Res 40: 188-207.

36. Jin Y, Liu BF (2010) The blog-mediated crisis communication model: Recommendations for responding to influential external blogs. J Publ Relat Res 22: 429-455.

37. Jin Y, LiuBF, Austin LL (2011) Examining the Role of Social Media in EffectiveCrisis Management: The Effects of Crisis Origin, Information Form, and Source on Publics'Crisis Responses. Commun Res 20: 1-21.

38. Kruckeberg D, Tsetsura K (2008) The "Chicago School" in the global community: Concept explication for communication theories and practices. Asian Communication Research 3: 9-30. 